Estudios sobre el Mensaje Periodístico ISSN-e: 1988-2696

http://dx.doi.org/10.5209/ESMP.55609

\title{
La revista Cine en 7 Días (1961-1973) y la crisis del star-system. Imágenes, personajes e historias de las estrellas en la prensa cinematográfica
}

\author{
Jorge Nieto Ferrando ${ }^{1}$
}

Recibido: 14 de enero de 2016 / Aceptado: 4 de julio de 2016

Resumen. Las revistas cinematográficas han sido durante mucho tiempo el principal medio a través del cual han llegado a los públicos las estrellas de cine. Buena parte de los estudios sobre las estrellas están sustentados en su utilización como fuente junto a las películas, pero en pocas ocasiones son las propias publicaciones las que centran la investigación. A través del análisis de los contenidos de la revista Cine en 7 Días este artículo reflexiona sobre la prensa cinematográfica como vehículo de transmisión de los textos publicitarios, informativos o literarios que alimentan el culto a las estrellas.

Palabras clave: Prensa cinematográfica; estrellas de cine; Claudia Cardinale; Elisabeth Taylor; Brigitte Bardot.

[en] The magazine Cine en 7 Días (1961-1973) and the star system crisis. Images, characters and stories of movie stars

\begin{abstract}
For a long time motion picture magazines have been the main medium through which film stars have been made accessible to the general public. A great part of the studies about these stars use these magazines as the main source for information, together with the movies, but only on a few occasions are the publications themselves the focus of research. Through the analysis of the contents of the magazine Cine en 7 Días, this article reflects on the motion picture press as a vehicle to transmit advertising, informative or literary texts that feed the star cult.
\end{abstract}

Keywords: Motion Picture Press; Movie Stars; Claudia Cardinale; Elisabeth Taylor; Brigitte Bardot.

Sumario. 1. Introducción. 2. Cine en 7 Días y la crisis del star-system. 3. Las imágenes, los personajes y las historias de las estrellas. 4. Claudia Cardinale, Elisabeth Taylor y Brigitte Bardot. 5. Conclusiones. 6. Referencias bibliográficas.

Cómo citar: Nieto Ferrando, Jorge (2017): "La revista Cine en 7 Días (1961-1973) y la crisis del star-system. Imágenes, personajes e historias de las estrellas en la prensa cinematográfica”, en Estudios sobre el Mensaje Periodístico 23 (1), 489-503.

\section{Introducción}

Las publicaciones periódicas han sido durante mucho tiempo — hasta la difusión de la televisión - el medio principal a través del cual han llegado a los públicos las estrellas de

\footnotetext{
$1 \quad$ Universitat de Lleida.

E-mail: nietojordi@filcat.udl.cat
} 
cine. Desde el momento en que, ya en los años veinte, la imagen de estas se construye a partir de los personajes que encarnan en las películas y también de las historias que protagonizan fuera de ellas, la prensa, en especial la cinematográfica, es esencial para permitir la "constante comunicación, oficial e íntima, con el reino de las estrellas". Las revistas "vierten sobre los fieles todos los elementos vivificantes de la fe: fotos, entrevistas, cotilleos, vidas noveladas, etcétera" (Morin, 1972: 59). Ningún estudio sobre las estrellas de cine omite el papel fundamental de la prensa cinematográfica en su creación y difusión (vid. Decordova, 1990; Sennett, 1998: 47-81; o Vincendeau, 2000:14-17), incluso muchos están sustentados en su utilización como fuente. Sin embargo, en pocas ocasiones son las propias publicaciones son las que centran la investigación ${ }^{2}$.

A partir del caso concreto de la revista española Cine en 7 Días, publicada entre 1961 y 1973 con periodicidad semanal bajo la dirección de Martín Abizanda, el objetivo de este artículo es analizar al papel de la prensa cinematográfica como vehículo de transmisión de los textos publicitarios - carteles, fotografías promocionales, etcétera - informativos — noticias, reportajes, etcétera - o literarios — biografíasque alimentan el culto a las estrellas; transmisión y también transformación, dado que estos materiales de partida son procesados por críticos y periodistas y convertidos en relatos a medio camino entre la ficción, la persuasión y la información. El objetivo del artículo son las estrategias empleadas por la prensa cinematográfica para generar las imágenes de las estrellas y para convertirlas en personajes principales de sus propias historias. Todo ello, además, en un momento muy concreto, el de la crisis del sistema que sustentaba el estrellato a finales de los años cincuenta.

Para ello se han elaborado los índices de los 661 números de Cine en 7 Días. A partir de aquí han sido identificadas las principales estrellas que protagonizan sus páginas, y han sido seleccionadas tres de las más asiduas: Claudia Cardinale, Elisabeth Taylor y Brigitte Bardot. Como veremos en el último epígrafe, a cada una, además, se le asocian unos atributos diferentes. Finalmente, se ha procedido al análisis de los procedimientos de índole narrativa empleados por la revista para relatar las historias de las estrellas y cómo, a partir de estas, y también de la fotografía, son construidas sus imágenes.

Se prefiere abordar con cierto detalle el caso concreto de la revista Cine en 7 Días, antes que dispersar el análisis en las numerosas cabeceras dedicadas casi en su totalidad a las estrellas. Las razones se deben a la encrucijada en la que se encuentra la publicación, como veremos en el siguiente epígrafe. Por una parte, Cine en 7 Días retoma y actualiza la manera en que son narradas las estrellas desde mediados de los años veinte; por otra, puede considerarse un antecedente del tratamiento que recibirán a partir de los años ochenta no solo las estrellas cinematográficas sino también otras celebridades, donde prima la confusión entre el ámbito de lo público y lo privado.

\section{Cine en 7 Días y la crisis del star-system}

Cine en 7 Días surge cuando la prensa cinematográfica generalista está en crisis en España. Sus contenidos se repartían entre los textos reflexivos sobre estética e

2 Algo diferente sucede con las publicaciones dedicadas a las celebridades, que comparten muchos aspectos con las cinematográficas. La prensa del corazón española, por ejemplo, ha sido abordada por Gómez Mompart (1992) o Pizarroso y Rivera (1994), entre muchos otros. 
ideología, la crítica de cine, cierto interés por cuestiones de cinematografía y, sobre todo, el tratamiento de las estrellas. En los primeros años de la década de los sesenta desaparecen cabeceras adscritas a este modelo nacidas tras la Guerra Civil como Primer Plano, Radiocinema, Imágenes y Cine Mundo. Solo sobrevive Fotogramas. Comienza en estos momentos a desarrollarse una prensa cinematográfica más especializada -Documentos Cinematográficos, Film Ideal, Nuestro Cine o Cinestudioen la que imperan la crítica y la reflexión cinematográficas, quedando desatendidas las estrellas. El modelo generalista de prensa cinematográfica, hegemónico entre los años veinte y finales de los cincuenta, no vuelve a recuperarse, al menos en cuanto al número de cabeceras, hasta la década de los ochenta.

Por otra parte, la vida de Cine en 7 Días discurre en un momento en que el estrellato deja atrás su edad dorada - también entre los años veinte y los cincuenta-. Perviven las estrellas pero desaparece, al menos en parte, el sistema que las sustentaba —el star system - . Las estrellas, además, comienzan a volverse más problemáticas: "El público continúa alimentándose con sus vidas; pero no se saborea ya el elixir prometedor de felicidad, ni la buena vida por su persona interpuesta; el alimento viene de sus dramas, su miseria. [...] El universo de Hollywood [antes] era maravilloso porque estaba filtrado, perfumado, euforizado por los cuidados del star system y de la cultura de masas" (Morin, 1972: 134-135).

Sin duda a ello contribuye la diversificación de las opciones de ocio con la difusión de la televisión, la música popular o el deporte de masas, que tienen capacidad para crear sus propios firmamentos. Durante mucho tiempo las estrellas cinematográficas nutrieron de personajes a las celebridades, hasta tal punto que podían casi equipararse unas y otras. La aparición de otro tipo de famosos ya en los años cincuenta acabará por desplazar - al menos en España- a los provenientes del cine. Esto puede apreciarse muy bien en las revistas del corazón. Desde los años cuarenta las estrellas de cine ocupan buena parte de las páginas de Hola, Semana o Lecturas. A principios de los años cincuenta, en Lecturas, por ejemplo, incluso sus cubiertas son copadas por estrellas como Grace Kelly, Gina Lollobrigida, Sofia Loren o Brigitte Bardot. En la década siguiente esta revista busca sus personajes también en la música popular y la televisión y, ya en los años setenta, solo aparecen en las cubiertas de manera recurrente tres actrices: Marisol, Rocío Dúrcal y Concha Velasco. La propia Cine en 7 Días acaba orientando parte de sus páginas hacia la música y la televisión, primero a través de secciones específicas y más tarde con artículos y reportajes independientes.

Pero también puede apreciarse en la revista cómo, ya en la segunda mitad de los años sesenta, resulta difícil encontrar personajes asiduos cuya imagen cumpla con los requisitos estelares, donde en estos momentos priman la cotidianeidad y la polémica. Las principales estrellas que protagonizan sus páginas provienen de la década anterior. Las que nacen en estos momentos, como Claudia Cardinale, apenas pueden sustentar su imagen en una vida extrafílmica agitada, por mucho que la revista dedique muchos esfuerzos para atribuírsela. Cine en 7 Días resuelve este problema además de con los artículos sobre música y televisión - con una mayor abundancia de reportajes fotográficos dedicados a las starletts, con un aumento de las páginas que atienden a los intérpretes españoles y, sobre todo a partir de 1970, con cierto regreso a las películas y los directores.

En los años sesenta, además, aparece el denominado "cine de autor", menor en términos económicos en comparación con las películas de Hollywood y sustentado 
en ocasiones en una concepción del cine como arte. El interés que generan sus películas está fundamentado en el tratamiento innovador de temas poco abordados con anterioridad y en el prestigio de sus directores. El nuevo cine no requiere de grandes figuras y, al menos en principio, tampoco puede permitírselas, aunque en ocasiones podrá crearlas — reciben trato como tales en Cine en 7 Días Jeanne Moreau, emblema de la Nouvelle Vague, o Mónica Vitti, por ejemplo (Abizanda, 1966; "Monica, sus horas bajas", 1968; "Entrevista con Jeanne Moreau", 1971; o Alba, 1961) - y algunas de las ya consolidadas acudirán en busca de prestigio a sus producciones. Muchos textos de la revista se esfuerzan en encontrar futuras estrellas en este nuevo cine, pero por "nuevo" se entiende más bien "cine del momento", dado que las actrices que lo protagonizan apenas intervienen en las propuestas cinematográficas más innovadoras de la década de los sesenta, o a lo sumo pueden considerarse todavía starletts o simples actrices. Es indudable que la relevancia de este cine, y la difusión de paradigmas críticos que ponen el acento en el director — que convierten al director, ahora denominado autor, en la estrella - a la hora de atender incluso al cine $m a-$ instream, influye en la ya comentada especialización de la prensa cinematográfica.

Cine en 7 Días es, además, una publicación cinematográfica cercana a la prensa del corazón. De hecho, sus años de existencia coinciden con el periodo de "consolidación” (1957-1966) y “expansión” (1967-1976) de esta, según la cronología establecida por Gómez Mompart (1992: 55). Como en la prensa del corazón (ibíd.: 50), también podemos detectar en ella las herencias provenientes de la mitología clásica, los folletines decimonónicos, los chismorreos de mentideros del siglo XVIII, la novela rosa, las crónicas de sociedad y la denominada "prensa femenina". Esta última, por ejemplo, aporta su tono intimista y el predominio de los temas tradicionalmente considerados femeninos, vinculados al ámbito de lo privado. Pero sin duda el vínculo con la prensa del corazón más destacable es apreciable en el predominio absoluto de los personajes de las estrellas sobre las películas u otros asuntos propios del cine y la cinematografía. La crítica queda reducida a una sección. Los textos dedicados a las películas, cuando aparecen, tienen fines publicitarios y siempre quedan supeditados a los estrellas.

Esto puede apreciarse muy bien con un ejemplo. En el número 93 (1963) la revista publicita El gatopardo (Il gattopardo, Luchino Visconti, 1963) de la siguiente manera:

Un traje con 50 metros de tul.

Claudia Cardinale entre Burt Lancaster y Alain Delon.

La Sicilia romántica y sangrienta de Garibaldi en la pantalla (Cine en 7 Días, 1963 :

“Claudia Cardinale entre Burt Lancaster y Alain Delon”. Núm. 93, pp. 12-13)

Casi todos los títulos de los artículos en Cine en 7 Días aparecen estructurados como los titulares de una noticia — con su antetítulo, título y subtítulo_-, independientemente de si corresponden a noticias, reportajes o entrevistas. Cuando el artículo está dedicado a una película, la referencia a la misma queda en el subtítulo, que aquí solo remite al espacio y el tiempo en el que está ambienta su historia, a pesar de que el cuerpo del texto evidencie que el tema central es El Gatopardo. El titular es reservado en exclusiva a las estrellas. Lo frecuente es que el contenido del artículo acabe derivando también hacia la estrella — este caso es una excepción-, a alguna 
vicisitud que haya padecido en el rodaje, destacando siempre cualquier situación conflictiva que pueda darse o el periodista intuya, o a la relación que guarda el personaje que interpreta con su personaje e imagen como estrella. Podría decirse que todos los contenidos parten de la estrella y concluyen en ella.

Es indudable que en las publicaciones de este tipo el personaje — asiduo, esporádico y efímero en función de la frecuencia de aparición en sus páginas - y la revista se necesitan mutuamente. La revista permite al personaje mantenerse en la agenda pública, lo que puede favorecerle en otros ámbitos de su vida profesional, y este contribuye a su difusión. Además de los contratos con representantes o productoras destinados a la promoción y la publicidad de las estrellas o sus películas - y sin salirse en muchos casos de estos-, los hechos que justifican la presencia de un personaje en las páginas de Cine en 7 Días pueden ser de índole privada —una nueva relación sentimental - o pública —el estreno de una película - : los primeros no suelen ser relevantes en sí mismos sino porque están protagonizados por las estrellas; el tratamiento de los segundos suele acabar también en el ámbito de lo privado ${ }^{3}$. Esto hace que la revista diluya la diferencia que algunos autores establecen entre celebridades, caracterizadas por un alto grado de exposición pública de su vida fuera de la pantalla, profesionales o actores (Geraghty, 2000: 187-196), dado que también intenta convertir las dos últimas categorías en celebridades.

\section{Las imágenes, los personajes y las historias de las estrellas}

Podríamos definir la imagen de una estrella como las concepciones generadas en los públicos sobre esta de manera que les permiten identificarla y diferenciarla respecto a otras estrellas. La construcción de la imagen de la estrella está sustentada en las informaciones fragmentadas de las historias extra fílmicas que protagoniza, en sus películas, sus fotografías, etcétera, y es resultado de la simplificación de un conjunto de atributos que se le asocian y acaban por conformar una totalidad más o menos coherente. Shingler y Gledhill (2008: 67-68) diferencian entre las nociones de personalidad - "A collection of surface traits by which a person becomes known (that is, the psychological, cognitive, emotional and physical characteristics of an individual)"-, personaje - "A more crafted and consolidated public projection of the person, in which film roles and media appearances play a part in creating the mask that ensures consistency, which can be used as an element of performance"- $y$, muy cercano al anterior, imagen: "This contains some star attributes and aspects of roles but also what is circulated in publicity, what is said and valued or criticized in reviews. This is the conceptualization of critics, fans and the public, projecting onto the star specific ideals, aspirations, desires, and so on".

Dado que nos situamos en el ámbito de la recepción, la imagen de la estrella no está controlada en su totalidad por la industria. En primer lugar, los medios de comunicación, y más aún la prensa cinematográfica, ya concretan, tamizan o modifican las imágenes propuestas. Estas, a través de las películas y de los materiales que generan las productoras, no necesariamente son la única fuente de información

Así ocurre, por ejemplo, con Monica Vitti, miembro del jurado en el festival de Cannes de 1968. Este acontecimiento es apenas una excusa para que la actriz, como narradora autodiegética, reflexione sobre su forma de ver el mundo y sus gustos personales ("Yo, jurado en Cannes", 1968). 
a la que recurren los periodistas. En el proceso de formación de las estrellas desde el principio los estudios idearon biografías que, en función de su criterio, podían ser útiles para la promoción de los actores o actrices y con ellos de sus películas. También ejercieron cierta vigilancia sobre la información que podía llegar a la prensa (Basinger, 2007: 49-52). No obstante, determinados acontecimientos escaparon a su control - la muerte de una estrella, por ejemplo_-, aunque bien pudieran influir con posterioridad en su tratamiento o fueran aprovechados con fines promocionales. En segundo lugar, debemos diferenciar la recepción de la estrella en la prensa cinematográfica y la recepción de la estrella a través de la prensa cinematográfica. De hecho, la imagen propuesta por la prensa también está sometida a la concreción por parte de los públicos, y esta puede variar en función del contexto desde el que actúan como tales o de parámetros sociológicos, entre muchos otros (Dyer, 1987).

El primer elemento para la creación de la imagen de la estrella es la fotográfica glamurosa. Como afirma Jacques Aumont (1998: 66), el glamour — "encantamiento"- nace de la necesidad de publicitar las películas cuando este cometido es encargado a los actores y las actrices: "El glamour es, sobre todo, una sensualidad registrada en la foto, en la misma materia fotográfica, como luz, como centelleo [...], que aumenta y pone de relieve la sensualidad de las materias fotografiadas, seda y satén, carne, ojos lánguidos, bocas generosamente maquilladas". El autor considera también que el glamour fue evolucionando, y "a un glamour 'dulce', que daba a los rostros un aspecto soñador, predominante durante los años veinte, sucedió un estilo más duro, más directo, más dramatizado y, hay que decirlo, más expresionista" (ibíd.; vid. Gundle, 2008). Si bien no le es exclusivo, el glamour parece más apreciable en el primer plano. Algunos autores consideran, siguiendo de cerca las reflexiones de Bela Balázs (1972), que resulta esencial el desarrollo de este tipo de planos en el cine para suscitar el fenómeno de la estrella cinematográfica, dado que enfrenta cara a cara al espectador con el artista, aísla su personalidad, apariencia y especificidad (Walker, 1970: 5, en Dyer, 2001: 30-31). Apenas extraña el uso recurrente del primer plano en las cubiertas de las revistas cinematográficas dedicadas a las estrellas.

La fotografía es esencial en Cine en 7 Días. Buena parte de sus páginas están confeccionadas para ser vistas antes que leídas, de ahí que, sobre todo en los reportajes fotográficos, reduzcan en ocasiones el texto escrito a pie de imagen. Las fotografías pueden depender de acontecimientos o no. Los acontecimientos provienen del ámbito laboral — rodajes, estrenos, galas benéficas, etcétera-o privado — eventos familiares, viajes de vacaciones, etcétera- Si bien en el primer caso el hecho y el personaje - un festival de cine y las estrellas que asisten al mismo-justifican la fotografía en las páginas de la revista, en el segundo prima en exclusiva el personaje. Pero Cine en 7 Días también publica fotografías no directamente vinculadas a acontecimientos. La mayoría son retratos y tienen por función la identificación del personaje, dado que buscan dotar de una identidad visual al actor o la actriz.

Los retratos destacan sobre todo en las cubiertas. En la mayoría de las revistas cinematográficas españolas generalistas anteriores están protagonizadas por primeros planos abiertos y planos medios de las estrellas, con algún que otro plano americano y plano general. En Cine en 7 Días esta relación se invierte, y los planos generales y los planos americanos son los más habituales. Ello es así en gran medida porque permiten apreciar el cuerpo de las actrices en un momento en que el erotismo es una de las últimas bazas del estrellato. De hecho, estas son presentadas, en especial desde 1965, como pin-ups. Dyer (2001: 73-74) insiste en la necesidad de diferen- 
ciar la pin-up como tipo, donde sitúa a Marilyn Monroe - "como modelo social, la pin-up promueve la apariencia superficial y la despersonalización, la mujer como un espectáculo sexual, como un objeto sexual"-, de la fotografía pin-up. Estas son imágenes sugerentes y cargadas de erotismo, propias, aunque no exclusivas, de las aspirantes al estrellato y de las estrellas en ciernes, las denominadas starletts, y por tanto suelen estar protagonizadas por actrices escasamente conocidas por el público. Las estrellas consagradas también pueden volver a recurrir a este tipo de fotografías, en especial cuando buscan reactivar su carrera o replantear su imagen. Las imágenes que protagonizan las cubiertas de Cine en 7 Días serán cada vez más atrevidas en la presentación de los cuerpos de las estrellas.

Si bien la fotografía de la estrella es un elemento clave de su imagen, esta se infiere sobre todo de las historias que protagonizan. La narración de dichas historias recurre a infinidad de estrategias, donde no son menores las propias de géneros como el melodrama, sobre todo aquellas que tienen que ver con la anagnórisis: el secreto revelado, la confesión, la confidencia, etcétera. Todas las historias contienen su correspondiente conflicto dramático. Tampoco falta la dosificación serial. En algunas ocasiones la historia es presentada mediante capítulos consecutivos que mantienen entre sí lazos causales y temporales; en otras, sin embargo, el espectador la construye a partir de episodios independientes, pequeños fragmentos e informaciones muchas veces redundantes, incluso con referencias explícitas o implícitas a artículos publicados con anterioridad.

Pueden ser historias sin final, diluidas si la estrella deja de ser rentable para la publicación o la industria, o que concluyen cuando, una vez alcanzada la fama, abandona con todo boato su actividad pública o fallece. En estas ocasiones las revistas disfrutan de algunos de sus grandes momentos ${ }^{4}$. Pero la desaparición de las estrellas siempre es temporal, y regresan para protagonizar reportajes de cariz evocador, aproximaciones a la evolución del estrellato, comparaciones con las estrellas actuales o calibrar el efecto que todavía generan en el público (vid. Singer, 1961; "Ventana al pasado", 1966; "Su nombre era Humphrey", 1970; Abizanda, 1971; o Pages, 1971). No es un hecho menor que buena parte de estos textos que miran al pasado con nostalgia sean frecuentes en Cine en 7 Días desde finales de los años sesenta, cuando ya resulta complicado encontrar entre los actores y actrices del momento posibles estrellas, al menos equiparables a las que habían protagonizado el estrellato en las décadas anteriores.

La imagen de la estrella encarna tipos sociales o conceptos idealizados sobre comportamientos. La estrella los personaliza al generar su propio personaje, cuyas características coinciden en líneas generales con las atribuibles a los personajes de la ficción, tal como fueron concebidos desde la novela burguesa decimonónica. Los personajes de las estrellas son singulares, autónomos - dado que parecen tener "vida propia"-, complejos al estar caracterizados por múltiples rasgos, y susceptibles al desarrollo y al cambio. También poseen una vida interior, realizan actos motivados, son coherentes y despiertan la identificación, primer paso para la imitación (Dyer, 2001: 122-131). Como afirma Dyer (ibíd:: 126), "la concepción burguesa del personaje intenta producir personajes que sean únicos e individualizados. Sin embargo, no tan únicos e individualizados para estar más allá de la comprensión o de la representatividad".

$4 \quad$ Así sucede, por ejemplo, con la muerte de Marilyn Monroe desde el número 70 (1962). 
En la construcción de la imagen de la estrella en la prensa cinematográfica intervienen todos los géneros periodísticos, pero sin duda muy relevantes son la entrevista y el reportaje. Ambos constituyen el instrumento básico para contar sus historias: permiten la individualización de la estrella, en ocasiones dejan entrever su complejidad, su vida propia e interior, los posibles cambios que experimentan a lo largo del tiempo, aportan coherencia y permiten la identificación. Cada nuevo acontecimiento narrado contribuye a la caracterización de la estrella, a dotarla de coherencia como personaje y a establecer las fronteras de lo que es verosímil en relación con sus próximas acciones. Dicha coherencia es lo que permite inferir una motivación a sus acciones: puesto que son así, actúan así. Los acontecimientos que protagoniza la estrella no son casuales, azarosos o caprichosos $-\mathrm{y}$ si lo son, tampoco importa-, sino que responden a ciertas reglas narrativas.

A la hora de aproximarse a la manera en que son narradas las historias de las estrellas en Cine en 7 Días podemos encontrar dos patrones argumentales recurrentes: el ascenso y el precio del triunfo. Las historias que rigen ambos patrones pueden confluir, ya que el ascenso tal vez conduzca al exceso, y este se paga caro. En el primero, sustentado en la movilidad social — tan propio del capitalismo avanzado que genera la estrella como el consumismo o el ocio, en el que en ocasiones también pone el énfasis su tratamiento-, es apreciable la "cotidianeidad" de la estrella, valor en alza en estos momentos. Las estrellas son más normales de lo que parecen, incluso surgen desde muy abajo hasta alcanzar las alturas del estrellato. Buena parte de los textos dedicados a ellas abordan sus biografías incidiendo siempre en su partida desde el anonimato. Tal como señala Richard Dyer (2001: 61), "el mito del éxito, particularmente en el Star System, intenta armonizar distintos elementos contradictorios: que la normalidad es el sello de la estrella; que el sistema premia el talento y la 'singularidad'; que los golpes de suerte, al alcance de cualquiera, tipifican la carrera de la estrella, y que el duro trabajo y la profesionalidad son necesarios para el estrellato".

La crisis del star system hacia finales de los cincuenta, acompañado por algunas sonadas tragedias — las muertes de James Dean (1955) y Marilyn Monroe (1962), por ejemplo_-, acrecientan la atención a los aspectos oscuros de la fama. Evidentemente no desaparecen los artículos amables, que muestran las curiosidades de unas vidas armoniosas y lujosas, pero el sufrimiento y los conflictos de las estrellas generan cada vez mayor interés. De hecho, cuando no existen, el periodista los busca o sospecha de su existencia. Los conflictos, la base de sus historias, pueden ser interiores, de situación, de relación, sociales o cósmicos. Las estrellas son las que generan sus propios problemas, sus complicaciones, debido a sus inseguridades, sus excesos y vicios - conflicto interior_- pero estos también están condicionados por el mundo fastuoso en el que viven - conflicto de situación-, lleno de rivalidades profesionales y sentimentales — conflicto de relación_- por la necesidad de afirmarse frente al grupo y sus convenciones - conflicto social — o por una fuerza superior a la que es imposible escapar: el inefable destino — conflicto cósmico-. Como veremos, las historias de las estrellas pueden discurrir de un conflicto a otro.

Las historias que concretan ambos patrones son abordadas en muchas ocasiones apelando a la verdad y la confidencia. A pesar de recurrir a numerosas estrategias de la ficción, el lector asume o finge asumir que dichas historias son veraces, que informan sobre o comentan acontecimientos que han tenido una existencia en la realidad. Puede afirmarse que el efecto de real es equivalente al conseguido por el docudrama; 
o en otras palabras, que la realidad de las estrellas aparece docudramatizada. Al mismo tiempo, se genera la expectativa en el lector de que la historia irá a la entraña del personaje, escarbará más allá de lo que es conocido del mismo, y aportará algunas informaciones que matizan el brillo del olimpo y lo sitúan al alcance de su mano. Este efecto se acrecienta en gran medida combinando los patrones argumentales mencionados con el papel de narrador autodiegético de la propia estrella ${ }^{5}$, ya sea a través de la entrevista o de algunos reportajes, o dejando la función de narrador a personajes que le son cercanos, del entorno más próximo y privado de la estrella. Las narraciones homodiegéticas, sin embargo, más que narrar el ascenso a la fama o su precio, permiten el acceso a lo más cotidiano e íntimo de las estrellas a través de un testigo privilegiado (Puyuelo, 1961; o "Diario de mi mujer", 1961).

\section{Claudia Cardinale, Elisabeth Taylor y Brigitte Bardot}

Veamos cómo se concreta lo comentado hasta aquí en el tratamiento que reciben Claudia Cardinale, Elisabeth Taylor y Brigitte Bardot en Cine en 7 Días.

Claudia Cardinale, a diferencia de Elisabeth Taylor y Brigitte Bardot, despunta como estrella en la década de los sesenta, cuando ya el sistema que sustenta el estrellato está agotado. La primera aparición de relevancia de la actriz en las páginas de Cine en 7 Días la encontramos en el número 19 ("Para relevar a Gina y a Sofia", 1961), donde se hace referencia a los factores que le han permitido llegar a la fama, entre los que destaca la necesidad de la industria del cine en Italia de buscar recambios para Sofia Loren y Gina Lollobrigida. Son muy frecuentes en la revista los artículos que buscan sustitutas a las estrellas consagradas, incluso sus reencarnaciones, entre las starletts, las actrices o las nuevas estrellas (Halpern, 1962; o "Marilyn 72", 1972). Pocos años más tarde el descubrimiento de Cardinale es transformado en una sofisticada estratagema para desbancar a las mencionadas estrellas, a la que se añade una supuesta rivalidad por el trono estelar europeo con Brigitte Bardot (Hierro, 1967).

En los artículos mencionados aparece el conflicto de relación con otras actrices. No obstante, la mayoría de las aproximaciones a la vida de Cardinale recurren al patrón argumental del ascenso aportando nuevos detalles de su biografía. La imagen que esta genera incide en su cotidianeidad: es presentada como una muchacha corriente (Sartorio, 1966), muy dependiente de su familia y amigos, llena de defectos físicos de los que es consciente ("Radiografía indiscreta...", 1962), aunque con un trabajo excepcional. Algún artículo, además, plantea la diferencia entre la imagen sugerida por los personajes que interpreta en sus películas, incluso por la publicidad, y la de su propio personaje extracinematográfico: "Las dos o tres películas suyas que conocemos nos la muestran como una criatura de carácter atrevido y naturaleza frívola e inconsciente. Sucede lo contrario, C.C. [...] es una muchacha tímida, silenciosa y formal [...]. La presencia de Claudia Cardinale nos prueba que se puede ser rico, cuerdo y bueno al mismo tiempo. Es muy difícil, sin embargo, que [...] el público acepte estas cualidades" ("Claudia Cardinale", 1963).

Los ejemplos son numerosos, en especial en los primeros años de la revista: "Yo fui un delincuente", 1961; "Mi verdadera vida", 1962; "Yo, por Jean Simmons", 1962. 
Una vida sin polémicas resulta poco atractiva para los lectores. La revista pronto busca rumores sobre algunas relaciones sentimentales, distorsiones en su imagen de chica sencilla: el silencio de la actriz a causa de un posible accidente en el rodaje de Mando perdido (Lost Command, Mark Robson, 1966) (Zalacain, 1965), los problemas que le pueden generar el divorcio de Franco Cristaldi, su prometido ("Claudia Cardinale y el productor...", 1966), o el descuido de su figura ("Carta a Claudia Cardinale", 1967). Tras algunas entrevistas en las que el personaje incide todavía más en su imagen cotidiana, sencilla y familiar, y después de su matrimonio con Franco Cristaldi, la historia de Cardinale se diluye y aparece ya casi en exclusiva para promocionar y publicitar algunas de las películas que protagoniza.

El principal conflicto de Liz Taylor es contra una fuerza sobrenatural, el destino trágico, aunque también podemos encontrar algunos conflictos emanados de la situación en que desenvuelven sus historias las estrellas. "Cleopatra Taylor'. Reposo absoluto" (1962), por ejemplo, insiste en ciertos rumores, gestados por los publicistas con el objetivo de entorpecer su carrera, sobre sus problemas de salud o un posible embarazo, lo que perjudicaría el largo rodaje de Cleopatra (Joseph L. Mankiewicz, 1963), o las supuestas aventuras extramatrimoniales de Eddie Fisher, su marido.

El destino trágico es presentado como el precio a pagar por la fama. Nacida en el seno de una familia acomodada y niña prodigio, a los doce años comienza una carrera llena de éxitos profesionales. Sin embargo, su salud es frágil, no ha podido disfrutar de una adolescencia feliz y desde los dieciocho años encadena matrimonios desgraciados: con Conrad Hilton, heredero de los famosos hoteles, con el actor británico Michael Wilding y con Mike Todd, hombre hecho a sí mismo y muy del agrado del público estadounidense, que muere al año de matrimonio. Además, dos de sus amigos más cercanos, James Dean y Montgomery Clift, sufren graves accidentes de automóvil. Todos estos hechos la convierten en un personaje melodramático, y como tal superado por unos acontecimientos que no puede controlar. Los textos que abordan su biografía, muchos de ellos redundantes, insisten en el destino trágico que la rige, y la imagen que generan, cargada de patetismo, busca despertar conmiseración del lector ("Liz Taylor", 1961; "Liz Taylor, una bellísima...”, 1961; "Una Mujer marcada", 1962). La desgracia, sin embargo, no impide — más bien acrecienta — su enorme popularidad.

Conviene que nos detengamos en "Una mujer marcada. Elizabeth Taylor" (1962). Publicado por entregas entre los números 60 y 64 muestra una estructura marcadamente serial. Cada episodio concluye con un momento de especial intensidad dramática, a la manera de los cliffhangers de los seriales, para mantener el interés del lector por la siguiente entrega. Así, el número 60 presenta a la estrella como un imán para los desastres, comenta la buena recepción de sus primeras películas infantiles, para acabar por señalar que "el éxito logrado elevó a Elizabeth a la categoría de estrella. Tenía entonces doce años, la edad que los niños prodigios no tienen derecho a pasar. Pero Sara Taylor [su madre] tenía pergeñada una idea. En cualquier caso, el amaestramiento de Liz proseguiría, encerrada en una jaula dorada". Se emplea el recurso a la anticipación que genera en el público la expectativa del cumplimiento en el siguiente episodio.

La siguiente entrega ( $\mathrm{n}^{\circ}$ 61) comienza con la voluntad de su madre, antigua actriz frustrada, de convertir todo lo relacionado con Taylor en publicidad, y las consecuencias personales para la actriz que ello conlleva. La conclusión en este caso es un potente revés: la depresión que sufre por el fin de su matrimonio con Hilton empieza 
a repercutir en su vida profesional, lo que conduce a que la MGM la envíe a Gran Bretaña para que tome distancia con el rodaje de Ivanhoe (Richard Thorpe, 1952). La tercera entrega ( $\left.n^{\circ} 62\right)$ acaba igualmente en un revés en el plano personal, la muerte de Todd, aunque en el profesional se abre la esperanza que supone el fin del contrato con la MGM.

Lo interesante es que el reportaje hace evolucionar la imagen de la actriz en la última entrega ( $\mathrm{n}^{\mathrm{o}}$ 64) narrando las vicisitudes de su matrimonio con Eddie Fisher, primero, casado y mejor amigo Mike Todd, su marido fallecido - este había sido presentado como el amor de su vida- y la relación sentimental con Richard Burton durante el rodaje de Cleopatra, que supone también la ruptura de su relación con Fisher y del matrimonio de Burton. En esta entrega confluyen su vida sentimental y profesional de una manera sin precedentes, y de una imagen sustentada en la compasión se pasa a otra bañada por la polémica, aunque pueda motivarse su comportamiento en los episodios previos de la historia que protagoniza: la tragedia personal conduce a la desesperación y ésta motiva actos poco meditados. Al mismo tiempo, su carrera profesional alcanza unas cotas desconocidas, siendo considerada la actriz mejor pagada del momento.

A partir de aquí Cine en 7 Días se interesa sobre todo por la relación de la actriz con Burton, destacando aquellos aspectos oscuros que encierra: el influjo que ejerce Burton sobre la estrella, que en sus entrevistas aparece insatisfecha con su vida (Hardtfield, 1965), los supuestos celos que siente de la actriz Geneviève Bujold durante el rodaje de Ana de los mil dias (Anne of the Thousand Days, Charles Jarrott, 1969), protagonizada por su marido, y que conduce a un pequeño ajuste de cuentas de la revista - "Y Elizabeth Taylor sabe que en cualquier momento habrá que pagar su deuda con el destino: 'ojo por ojo, diente por diente' y 'como midáis, seréis medidos', según la antigua e implacable filosofía” (Gavin, 1969: 27)—, o los problemas con el alcohol de la pareja (Ferron, 1967).

Al igual que había sucedido con Claudia Cardinale y su matrimonio con Franco Cristaldi, una vez la relación de Liz Taylor con Richard Burton se afiance la estrella reducirá sus apariciones en Cine en 7 Días a la promoción de las películas que protagoniza. Es indudable que la estabilidad sentimental, a pesar de dejar siempre resquicios para la polémica, hace perder fulgor a las estrellas, pero también lo es que poco a poco dejan de interesar al público sus historias tanto como antes. Así, Brigitte Bardot, que nunca renunciará al escándalo, también acabará limitándose a publicitar películas.

El conflicto de Brigitte Bardot es en gran medida de cariz social: la lucha por imponerse y reafirmarse en un contexto que todavía permanece marcado por corsés morales. La imagen de Bardot se asienta en el erotismo de su personaje, una de las últimas bazas, ya ensayada con Marilyn Monroe, para recuperar la atención sobre las estrellas y sus películas cuando lleva tiempo descendiendo la asistencia del público a las salas de exhibición. En ella confluyen con una coherencia desconocida en las anteriores los personajes que encarnó en sus películas — donde siempre protagoniza escenas de striptease — , la imagen fotográfica — nunca dejó de posar como una pinup mientras fue joven, encarnando también su tipo- y su historia confeccionada en las entrevistas y reportajes. La imagen de Bardot es la de la libertad, independencia y naturalidad, con buenas dosis de frivolidad, capricho y sensualidad, características asociadas, además, a su origen francés. Así, Sartorio (1963) afirma que, como francesa, muestra "un abierto sentido de la independencia. [...] No hay nada de círculos 
cerrados en torno a su figura; por principio no teme a nada ni a nadie. ¡Qué diferencia con sus colegas italianas, por ejemplo! Con Sofia Loren, bajo la mirada clueca de su marido, Carlo Ponti; con Gina [Lollobrigida], bajo la férrea presencia fiscal, delante o detrás de la cortina, de su esposo, Mirko".

Apenas extraña que sea el personaje más frecuente en Cine en 7 Días. Muchos textos intentan descubrir sus misterios, sobre todo su capacidad para influir en el público, en ocasiones desde las perspectivas más esotéricas. En "Brigitte Bardot. En sus peinados está la clave de su destino" (1963) se afirma, por ejemplo, que su cabello constituye todo un programa. Su tendencia a resaltar la parte posterior de la cabeza indica que se ama a sí misma por encima de todo — de ahí que necesite continua adulación —, que le importa poco lo que digan los demás a la hora de seguir sus impulsos. Esto constituye un peligro, dado que es justamente su peinado lo más imitado por las jóvenes de todo el mundo. A ello se añade que, por el hecho de haber nacido bajo el signo de libra, es una persona caprichosa.

Buena parte de los textos que abordan a Bardot insisten en su físico, que se considera creado y modelado por el director Roger Vadim, su descubridor y primer esposo ("El caso B.B.", 1963). Punto por punto son abordadas las transformaciones que ha ido experimentando, incidiendo en aquellas que le dan un aspecto, según se indica, "candoroso", la clave de su secreto: la boca voluptuosa con labios carnosos, los cabellos despeinados, las líneas sinuosas y gráciles o los “ojos inolvidables, largos, profundos, ingenuos y perversos, ojos de ángel y de demonio" (ibid.: 15). En el número 123 (C. S., 1963) aparecen algunos elementos más: su capacidad para combinar "la feminidad eterna y la belleza moderna", que llega a eclipsar los personajes que encarna en sus películas, y el hecho de que todo ello sea fruto de la publicidad: "Su belleza parece ser la que puede encontrarse [...] en la calle, y no da por tanto, esa sensación de "inaccesibilidad", de lejanía inalcanzable, propia de los productores norteamericanos del starsystem. Es un mito, pero un mito más fácil, más cotidiano: vivo y accesible”.

Con todo, algunas entregas de su historia comienzan a plantear la evolución del personaje. Esto puede apreciarse con motivo del rodaje de El desprecio (Le mépris, Jean-Luc Godard, 1963), película que formaba parte de ese nuevo cine centrado en el director que podía dar prestigio a las estrellas. En consonancia, se considera que con esta película comienza una nueva carrera para la actriz: la imagen erótica y moderna, ingenua y perversa — su mito era el de Lolita, se afirma — , ha quedado en el pasado (Agde, 1963). Pero nada cambia a la hora de publicitar la película:

Con aire cansado, roto...

Así ven a la inquieta Brigitte Bardot en Roma (Detalle de la película El desprecio, Jean-Luc Godard, 1963)

La estrella continúa ocupando el lugar central. Lo importante es su estado de ánimo, su "inquietud", coherente con la imagen elaborada de Bardot a través de las diferentes entregas que permiten construir su historia. Solo al final se habla de $E l$ desprecio. Si bien todavía protagonizará entrevistas, incluso narraciones homodiegéticas que contrapuntan su imagen ${ }^{6}$, su presencia en las páginas de Cine en 7 Días,

6 En "Ahora que no se nos oye. Hablan, revelan, suponen... Brigitte Bardot vista por su madre y por su mayordomo" (1965), su mayordomo la presenta como una persona ahorradora y equilibrada en su casa, en contraste con 
como la de Claudia Cardinale o Liz Taylor, quedará con el tiempo centrada en exclusiva en la promoción de las películas.

\section{Conclusiones}

La prensa cinematográfica desempeña un papel esencial en el fenómeno del estre1lato. Buena parte de los estudios sobre las estrellas acuden a ella como fuente. Las propias particularidades de las revistas cinematográficas, sin embargo, determinan la manera en que estas son procesadas a partir de los materiales publicitarios de las productoras y expuestas al público. Este artículo, a través del caso de Cine en 7 días, se ha propuesto transformar la mera fuente en objeto de análisis.

Cine en 7 Días es una revista crepuscular. Se publica en un momento en que el sistema que sustenta al estrellato está en crisis por la aparición de otras celebridades y otras maneras de entender el cine. Esto puede apreciarse en las historias de Claudia Cardinale, Liz Taylor y Brigitte Bardot. La primera muestra las dificultades para construir una estrella desde principios de los años sesenta, sobre todo por mantenerse dentro de los límites de la norma, cuya trasgresión es esencial en la elaboración de personajes que seduzcan al público (Marshall, 1997:105-107). Liz Taylor y Brigitte Bardot, que vienen de la etapa anterior, no dudan en quebrantar la norma moral. La primera ratifica la estrecha relación entre su agitada vida y su cotización como actriz; la segunda, además, encarna el tipo pin-up.

Hemos manejado aquí e interrelacionado las nociones de imagen de la estrella, personaje de la estrella e historia de la estrella. La imagen, entendida como la concepción de la estrella generada en los públicos, surge fundamentalmente de su personaje y de las historias extrafílmicas que como tal protagoniza. La noción de "imagen" está emparentada con el término homónimo empleado en el ámbito de la comunicación corporativa; de hecho, el aparato conceptual y las metodologías aplicados a esta deberían emplearse en el análisis del fenómeno del estrellato. Pero nos hemos centrado en la imagen sugerida desde las páginas de Cine en 7 Días. No se renuncia a abordar en otros trabajos revistas más recientes, lo que permitirá calibrar hasta qué punto puede corresponder la imagen sugerida por las publicaciones con la creada por los espectadores/lectores.

Las estrellas son personajes de historias; es decir, de series de acontecimientos ligados por relaciones causales en una progresión dramática hacia su conclusión, aunque en ocasiones el final quede diluido cuando la estrella deja de interesar a la publicación. Dichas historias recurren a patrones argumentales y conflictos propios de la ficción, aunque son tomadas por los públicos como veraces. Esto se aprecia especialmente la influencia del melodrama, sobre todo con el recurso a la anagnórisis y, en ocasiones, a personajes superados por los acontecimientos. Sus historias, además, son fragmentadas. En muchas ocasiones presentan una fragmentación serial, ya sea de manera formal si un reportaje se divide en diferentes entregas, o informal cuando, sin presentarse de manera serial, diferentes artículos, entrevistas o reportajes van añadiendo informaciones nuevas que permiten construir la historia de la estrella. Pero la fragmentación también implica a otros medios. Si bien nos hemos centrado

la imagen que desprenden otros episodios de su historia. 
en la prensa cinematográfica, y en concreto en el caso de Cine en 7 Días, los públicos también acceden a las estrellas a partir de fotografías, de sus películas, de sus apariciones en televisión - en anuncios, concursos, entrevistas, programas de sociedad, etcétera- e incluso a través de chismorreos y cotilleos. Esto nos permite afirmar que los relatos de las estrellas y, a partir de estos, la construcción de la historia por parte del receptor, son un antecedente de lo que hoy en día se denomina "narración transmedia".

\section{Referencias bibliográficas}

Abizanda, Martín (1966): "Monica, la esfinge”. Cine en 7 Días, 250, 12-13.

Abizanda, Martín (1971): “Todo un hombre. Gary Cooper”. Cine en 7 Días, 524, 17-19.

Agde, Paul (1963): “Con aire cansado, roto... Así ven a la inquieta Brigitte Bardot en Roma.

Detalle de su última película El desprecio". Cine en 7 Días, 112, 16-17.

Alba, Marcos (1961): "Nueva Monica Vitti”. Cine en 7 Días, 556, 8-9.

Aumont, Jacques (1998): El Rostro en el cine. Barcelona, Paidós.

Balázs, Bela (1972): Theory of the Film: Character and Growth of a New Art. New York, Arno Press.

Basinger, Jeanine (2009): The Star Machine. New York, Vintage Books.

Cine en 7 Días (1961): “Diario de mi mujer, por Bob Hope”. Núm. 5, 26-27.

Cine en 7 Días (1961): “Liz Taylor. ¿Es víctima de un destino incierto?”. Núm. 12, 14-15.

Cine en 7 Días (1961): "Yo fui un delincuente. Confesiones de Tony Curtis". Núm. 13-16.

Cine en 7 Días (1961): "Para relevar a Gina y a Sofia, Italia lanza a Claudia Cardinale" Núm. 19, 11-12.

Cine en 7 Días (1961): "Liz Taylor, una bellísima mujer víctima de su propio destino" (1961). Núm. 23, 16-17.

Cine en 7 Días (1962): “Cleopatra Taylor'. Reposo absoluto”. Núm. 41, 18-19.

Cine en 7 Días (1962): "Mi verdadera vida, por Marilyn Monroe” Núm. 43-45.

Cine en 7 Días (1962): "Yo, por Jean Simmons". Núm. 51, 20.

Cine en 7 Días (1962): “Una mujer marcada. Elizabeth Taylor”. Núm. 60-64.

Cine en 7 Días (1962): "Radiografía indiscreta de Claudia Cardinale". Núm. 65.

Cine en 7 Días (1963): "El caso B.B. Nuevo mito de Pigmalión. Núm. 92, 14-15.

Cine en 7 Días (1963): "Claudia Cardinale entre Burt Lancaster y Alain Delon”. Núm. 93, 12-13.

Cine en 7 Días (1963): "Brigitte Bardot. En sus peinados está la clave de su destino". Núm. 99, 6-7.

Cine en 7 Días (1963):“Claudia Cardinale. Una chica tímida convertida en vampiresa”. Núm. 100, 16-18.

Cine en 7 Días (1963): “Un escritor famoso, Marcel Achard, ataca a Brigitte Bardot”. Núm. 123, 15-17 (firmado por C.S.)

Cine en 7 Días (1965): “Ahora que no se nos oye. Hablan, revelan, suponen... Brigitte Bardot vista por su madre y por su mayordomo". Núm. 206, 12-15.

Cine en 7 Días (1966): "Claudia Cardinale y el productor Franco Cristaldi, ¿tendrán que renunciar a la nacionalidad italiana para casarse?”. Núm. 255, 18-19.

Cine en 7 Días (1966): "Ventana al pasado. Joan Crawford”. Núm. 293, 18-19.

Cine en 7 Días (1967): “Carta a Claudia Cardinale”. Núm. 313, 12-13.

Cine en 7 Días (1968): "Yo, jurado en Cannes. Habla Monica Vitti”. Núm. 374, 12-13. 
Cine en 7 Días (1968): "Monica, sus horas bajas”. Núm. 391, 20-21.

Cine en 7 Días (1970): "Su nombre era Humphrey”. Núm. 477, 20-21.

Cine en 7 Días (1971): "Entrevista con Jeanne Moreau” Núm. 513, 26-27.

Cine en 7 Días (1972): "Marilyn 72. Nació en El Salvador y fue descubierta en España". Núm. 567, 20-21.

Dyer, Richard (1987): Heavenly Bodies: Film Stars and Society. Basingstoke, Macmillan.

Dyer, Richard (2001): Las estrellas cinematográficas. Barcelona, Paidós.

Ferron (1967): “¿Alcoholizados? Una sombra amenaza la dicha de Liz Taylor”. Cine en 7 Días, $\mathrm{n}^{\circ} 342,14-15$.

Gallego, Juana (1990): Mujeres de papel. De iHola! a Vogue. La prensa femenina en la actualidad. Barcelona, Icaria.

Gavin, Mario (1969): "Liz Taylor, celosa de la actriz que interpreta el papel de Ana Bolena", Cine en 7 Días, núm. 429, 27.

Geraghty, Christine (2000): "Re-examining Stardom: Questions of Texts, Bodies, and Performance". En Gledhill, Christine; Williams, Linda (Eds.): Reinventing Film Studies. Londres: Arnold, pp. 183-201.

Gundle, Stephen (2008): Glamour: A History. Oxford, Oxford University Press.

Gómez Mompart, Josep Lluís (1992): "Medio siglo de prensa del corazón en España (19401990)". Anàlisi, 14, 47-59.

Halpern, F. (1962): "Ursula Andress. Actriz suiza, esposa de John Derek. La nueva Greta”. Cine en 7 Días, $\mathrm{n}^{\circ}$ 64, 10-11.

Hardtfield, Charles (1965): “¿Qué le pasa a Liz Taylor?”. Cine en 7 Días, núm. 232, 19.

Hierro, Galo (1967): “Operación C. C.”. Cine en 7 Días, núm. 318, 13 de mayo, p.18.

Marshall, David P. (1997): Celebrity and Power: Fame in Contemporary Culture. Minneapolis, University of Minnesota Press.

McDonald, Paul (2000): The Star system: Hollywood's production of popular identities. London, Wallflower.

Morin, Edgar (1972): Las stars. Servidumbres y mitos. Barcelona, Dopesa.

Pages, Eduardo (1971): “De Valentino a Delon”. Cine en 7 Días, núm. 534, 24-25.

Pizarroso, Alejandro y Rivera, Julia (1994): Corazones de papel. Sensacionalismo y prensa del corazón en España. Barcelona, Planeta.

Puyuelo, Marcela (1961): "Sofía Loren vista por su doncella". Cine en 7 Días, núm. 2.

Sartorio, L. (1963): "Memorias de Brigitte Bardot”. Cine en 7 Días, núm. 139, 13-15.

Sartorio, Dolores (1966): "Los puntos cardinales de Claudia". Cine en 7 Días, núm. 270, 14-15.

Singer, Jane y Kurt (1961): “Ayer y hoy de Greta Garbo". Cine en 7 Días, núm. 9, 4-6.

Shingler, M.; Gledhill, C. (2008). "Bette Davis: actor/star". En Screen, 49 (1), 67-76.

Vincendeau, Ginette (2000): Stars and Stardom in French Cinema. London/New York, Continuum.

Walker, Alexander (1970): Stardom: The Hollywood Phenomenon. New York, Stein and Day. Zalacain, A. (1965): "El "cardenal” de Claudia Cardinale, ¿es la causa del silencio de la actriz?”. Cine en 7 Días, núm. 220, 4-5.

Jorge Nieto Ferrando es Profesor Ayudante Doctor de la Facultat de LLetres de la Universitat de Lleida. 